\title{
THE QUALITY OF LIFE AND CONTENTMENT WITH THE REALISATION OF PARTIAL SATISFACTIONS OF STUDENTS FROM THE FACULTY OF PHYSICAL EDUCATION AND SPORT IN BIAŁA PODLASKA \\ The quality of life and partial satisfactions
}

\author{
MARIA ANNA TUROSZ, ANNA OLECH
}

\author{
The Josef Pilsudski University of Physical Education in Warsaw, Faculty of Physical Education \\ and Sport in Biała Podlaska, Department of Psychology
}

\author{
Mailing address: Maria Anna Turosz, Faculty of Physical Education and Sport, \\ Department of Psychology, 2 Akademicka Street, 21-500 Biała Podlaska, tel.: +48 83 3428778, \\ fax: +48 83 3428800, e-mail: anna.turosz@awf-bp.edu.pl
}

\begin{abstract}
Introduction. The aim of the work was to define the level of contentment with the realisation of partial satisfactions of female and male

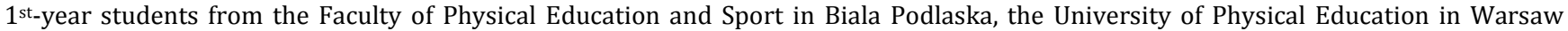
(FPES) demonstrating a high or low level of the quality of life. Material and methods. 44 women and 161 men were examined. At the first stage of the research the level of the quality of life was defined with the use of the Satisfaction With Life Scale (SWLS). At the second stage the level of contentment with the realisation of partial satisfactions of people with a high or low level of the quality of life was examined. The level of contentment with partial satisfactions was measured by means of a questionnaire in which partial satisfactions were grouped in 5 categories: social, material, environmental, health and other satisfactions. Statistically significant differences were defined with the use of Pearson's chi-square test $\left(\chi^{2}\right)$, taking values lower than the significance level $\mathrm{p}<0.05$ as statistically significant. Results. There occur statistically significant differences in the levels of contentment with the realisation of partial satisfactions of female and male students revealing a high or low level of the quality of life. Better material conditions, contentment with the way of spending free time, one's own life achievements and health are conducive to reaching a high level of the quality of life among students. Over $70 \%$ of the examined academic youth with a high level of the quality of life perceive their life as great and successful and the conditions in a family as positive. Over $60 \%$ of female students and $30 \%$ of male students from this group have very strong family bonds. Conclusions. The level of contentment with the realisation of partial satisfactions is connected with the system of values of an individual. Positive and strong family bonds favour a high level of the quality of life. The system of cultural institutions in Biala Podlaska as a university town should be developed more dynamically.
\end{abstract}

Key words: the quality of life, partial satisfactions, physical education students

\section{Introduction}

The term "quality of life" originates from the trend of positive psychology which examines and promotes the sources of human happiness; the first analyses in this field occurred in the middle of the $20^{\text {th }}$ century. Numerous scientists claim that its definition depends on opinions and points of view of an individual $[1,2,3]$ and requires a holistic and multi-dimensional approach [4].

Diner et al. [5] wrote that "the quality of life of individuals is determined mainly by the fact that they personally like it. Subjective well-being is defined as a cognitive and emotional evaluation of your own life. This evaluation includes both emotional reactions to situations and cognitive assessments concerning satisfaction and fulfilment". Happiness is equivalent to enjoying your own life [6]. A variety of the concepts of the quality of life results from numerous definitions and differences in scientists' opinions concerning the essence of happiness.
There occurred a suggestion to divide all the theories into the following categories: discouraging (e.g. genes, adaptation), encouraging (e.g. motivation) and comforting ones (e.g. "happy attractor") [7].

A leading concept in this research is a concept originating from the theory of a "happy attractor" being an equivalent to a potential level of happiness, i.e. An Onion Theory of Happiness by Czapinski [8], which describes well-being in 3 layers. The deepest layer, determined genetically, is the will of life. The intermediary layer is more subjective and includes a general life satisfaction. The layer which is most shallow and most sensitive to alterations is a sphere of partial satisfactions. According to this concept, the more internal, the more stabile and objective the layer $[1,6]$. This model shows that "people do not need to have any specific reason to feel happy, but they need to have a significant reason to feel unhappy" [8].

It seems significant both for cognitive and for practical reasons to diagnose the level of contentment of students with the 
realisation of their plans and aims in various spheres of life (partial satisfactions), since for the university it constitutes significant information which monitors the quality of its functioning so strongly highlighted in the Bologna Declaration and implemented in the European Higher Education Area. Additionally, it may become a starting point in the modification of these activities which are included both in the area of education and in the area of upbringing, and at the same time are conducive to subjective contentment with life of academic youth. "Every university should be interested in the constant improvement of the quality of work" [9]. It must be added that, apart from the research done by the author of the article [10,11,12,13], physical education students have not been characterised in the context of a psychologically understood quality of life, which seems to raise the cognitive value of the work.

The aim of the work was to define the level of contentment with the realisation of partial satisfactions of female and male $1^{\text {st }}$ year students from the FPES with a high or low level of the quality of life.

\section{Material and methods}

At the $1^{\text {st }}$ stage of the research the level of the students' quality of life was defined with the use of the Satisfaction With Life Scale (SWLS) [14]. The scale includes five statements and the subject evaluates his or her life according to seven categories from "strongly disagree" to "strongly agree". The result of the measurement is a general indicator of the satisfaction with life. A low level of the quality of life was noted in $36 \%$ of the female students and $26 \%$ of the male students, whereas a high level was observed in $34 \%$ of the female students and $25 \%$ of the male students. These students participated in the $2^{\text {nd }}$ stage of the research in which satisfaction with selected spheres of life and differences at the level of the analysed variables were defined with the use of selected questions from the questionnaire prepared by the founders of the Council of Social Monitoring and cooperating experts and applied in the Social Diagnosis 2009 [15]. The selection of particular questions was influenced by their reliability and accuracy assessed by experts. The analysis included, analogically to the Social Diagnosis 2009 [15], questions concerning the level of respondents' satisfaction with selected categories including various spheres and areas of life, i.e. social, material, environmental, health and other areas, inter alia one's own achievements, ways of spending free time, prospects for the future. The subjects' task was to define the levels of satisfaction with particular spheres of life according to six-degree scale from "very dissatisfied" to "very satisfied" with an additional category "does not apply". Additionally, subjects assessed the strength of family bonds in categories from "very week" to "very strong", the level of satisfaction with their life perceived globally in categories from "unhappy and horrible" to "great and successful" and the frequency of occurrence of suicidal thoughts in a previous month in the categories from "very frequently" to "never". The statistical significance was evaluated with the use of Pearson's chi-square test $\left(\chi^{2}\right)$.

\section{Results}

The examined groups with a high or low level of the quality of life did not differ in most categories in the assessment of their level of contentment with the analysed fields and dimensions of life. However, female and male students with a high level of the quality of life assessed the majority of categories more positively than the remaining groups (Tab. 1).

None of the subjects, regardless of gender and the level of the quality of life, was "very satisfied" and only a few were "satis- fied" with the situation in the country. Over a half of the students assessed the functioning of our country in negative categories. None of the female students was "very satisfied" with moral norms and access to culture. Regardless of gender and the level of the quality of life, circa $40 \%$ of the examined youth assessed the access to culture and services in the local environment negatively, while one third of them were dissatisfied to various extents with studying in Biala Podlaska as a university town.

A financial status clearly differentiated the examined groups. Over a half of both female and male students with a high level of the quality of life were satisfied with their material resources; however, as far as male students are concerned, the difference was statistically significant $(\mathrm{p}<0.001)$. Unfortunately, every fifth student with a low level of the quality of life complained about his financial situation.

While analysing partial satisfactions connected with the health of the respondents it was noted that none of the people with a high level of the quality of life evaluated their lifestyle as unhealthy, whereas it was indicated by half of the female students and every fifth male student with a low level of the quality of life. The majority of students achieving high satisfaction with life were content with their health $(\mathrm{p}<0.05)$.

Table 1. The level of satisfaction with the environmental, material and health dimension of the life of students with a high or low level of the quality of life $(n=124)$

\begin{tabular}{|c|c|c|c|c|c|c|c|c|c|c|c|c|c|c|c|c|}
\hline \multicolumn{17}{|c|}{ nvironmental dimension } \\
\hline & & 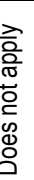 & & 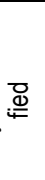 & & 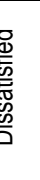 & 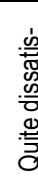 & & & 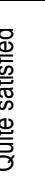 & & 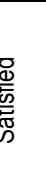 & & 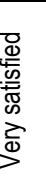 & உ \\
\hline & & \multicolumn{15}{|c|}{$\%$} \\
\hline & & $\mathrm{L}$ & $\mathrm{H}$ & L & $\mathrm{H}$ & L & $\mathrm{H}$ & $\mathrm{L}$ & $\mathrm{H}$ & L & $\mathrm{H}$ & $\mathrm{L}$ & $\mathrm{H}$ & $\mathrm{L}$ & $\mathrm{H}$ & \\
\hline \multirow{2}{*}{$\begin{array}{l}\text { Situation } \\
\text { in the } \\
\text { country }\end{array}$} & W & 10 & 0 & 13 & 14 & 50 & 20 & 25 & 53 & 6 & 13 & 0 & 0 & 0 & 0 & 0.555 \\
\hline & M & 2 & 3 & 31 & 22 & 29 & 25 & 26 & 22 & 12 & 20 & 0 & 8 & 0 & 0 & 0.575 \\
\hline \multirow{2}{*}{$\begin{array}{l}\text { Moral } \\
\text { norms }\end{array}$} & W & 0 & 0 & 0 & 0 & 19 & 7 & 31 & 20 & 44 & 47 & 0 & 26 & 0 & 0 & 0.858 \\
\hline & M & 0 & 0 & 5 & 5 & 12 & 7 & 26 & 17 & 36 & 41 & 17 & 27 & 4 & 3 & 0.909 \\
\hline \multicolumn{17}{|c|}{ Material dimension } \\
\hline \multirow{2}{*}{\begin{tabular}{l|} 
Financial \\
conditions
\end{tabular}} & W & 0 & 0 & 6 & 0 & 6 & 0 & 19 & 0 & 44 & 46 & 25 & 40 & 0 & 14 & 0.287 \\
\hline & M & 0 & 5 & 5 & 0 & 19 & 7 & 24 & 7 & 43 & 29 & 7 & 37 & 2 & 15 & 0.001 \\
\hline \multirow{2}{*}{\begin{tabular}{l|} 
Living \\
conditions
\end{tabular}} & W & 0 & 0 & 0 & 7 & 13 & 0 & 19 & 13 & 43 & 40 & 19 & 20 & 6 & 20 & 0.643 \\
\hline & $\mathrm{M}$ & 5 & 2 & 2 & 0 & 12 & 2 & 19 & 7 & 29 & 37 & 27 & 37 & 7 & 15 & 0.223 \\
\hline \multirow{2}{*}{$\begin{array}{l}\text { Access to } \\
\text { goods, } \\
\text { services, } \\
\text { culture }\end{array}$} & W & 0 & 0 & 19 & 13 & 6 & 0 & 25 & 27 & 50 & 33 & 0 & 27 & 0 & 0 & 0.555 \\
\hline & $M$ & 2 & 0 & 5 & 5 & 12 & 15 & 21 & 22 & 36 & 27 & 21 & 24 & 3 & 7 & 0.907 \\
\hline \multicolumn{17}{|c|}{ Health dimension } \\
\hline \multirow{4}{*}{$\begin{array}{l}\text { Healthy } \\
\text { lifestyle } \\
\text { Health }\end{array}$} & W & 0 & 0 & 6 & 0 & 13 & 0 & 31 & 0 & 19 & 53 & 31 & 33 & 0 & 13 & 0.092 \\
\hline & M & 5 & 0 & 5 & 0 & 2 & 0 & 14 & 5 & 26 & 22 & 34 & 46 & 14 & 27 & 0.224 \\
\hline & $\mathbf{W}$ & 0 & 0 & 6 & 0 & 6 & 7 & 0 & 0 & 6 & 21 & 75 & 50 & 6 & 22 & 0.649 \\
\hline & M & 0 & 0 & 0 & 2 & 3 & 0 & 5 & 5 & 27 & 2 & 46 & 51 & 20 & 39 & 0.041 \\
\hline
\end{tabular}

Key: W - woman; M - man; $\mathrm{p}$ - significance level; L/H - low/high level of the quality of life (\%)

In a further part, the analysis of these social dimensions of life which refer to direct contacts with people both in the social and in the intimate sphere was presented (Tab. 2, Fig. 1, Fig. 2). In a subjective evaluation of an individual, family bonds mark the closeness of family members and are an element of its integrity and a factor protecting the youth and serving as fundamentals for shaping safety and autonomy of an individual. While evaluating family bonds the answer concerned defining their strength (Fig. 1, Fig. 2).

All the female students with a high level of the quality of life evaluated their bonds with other people in a family positively 
$(\mathrm{p}<0.05)$, while it is worth highlighting that over a half of the examined women were strongly bound with their closest relatives in the sphere of thoughts, emotions and accepted values. Similar regularities were observed while analysing the results of the research concerning the strength of family bonds among $1^{\text {st }}$-year male students (Fig. 2).

Men with a high level of the quality of life were mostly satisfied with their relations with the closest relatives, whereas almost every third of them assessed his level of family affiliation as "very strong" $(\mathrm{p}<0.01)$. The research confirmed (Tab. 2) that with regard to the majority of respondents with a high level of the quality of life, their subjective evaluation of family relations was very positive $(\mathrm{p}<0.01)$. These young people - future teachers and role models for children and youth - grew up in families full of kindness, acceptance, friendship and partnership, where mental needs of the family members were fulfilled.

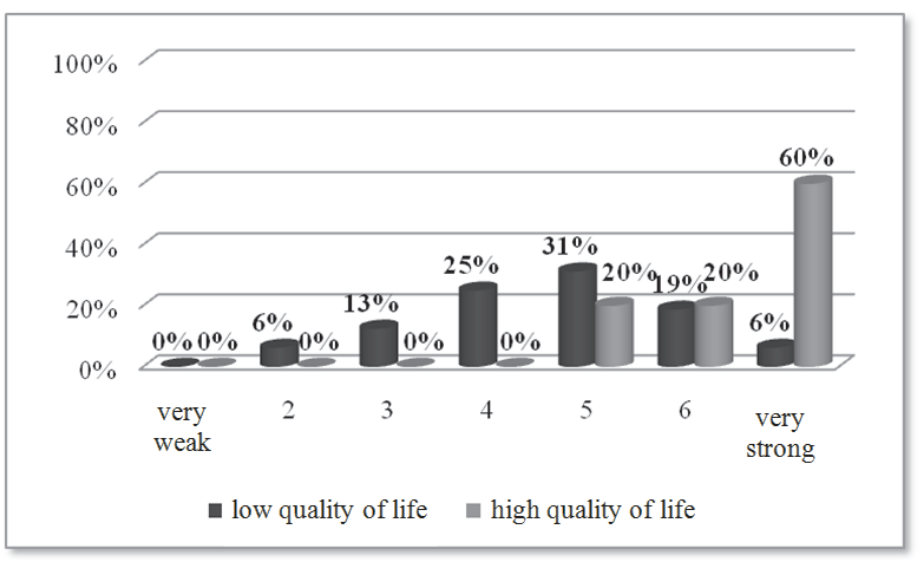

Figure1. The assessment of family bonds of female students with a low or high level of the quality of life $(n=31)$

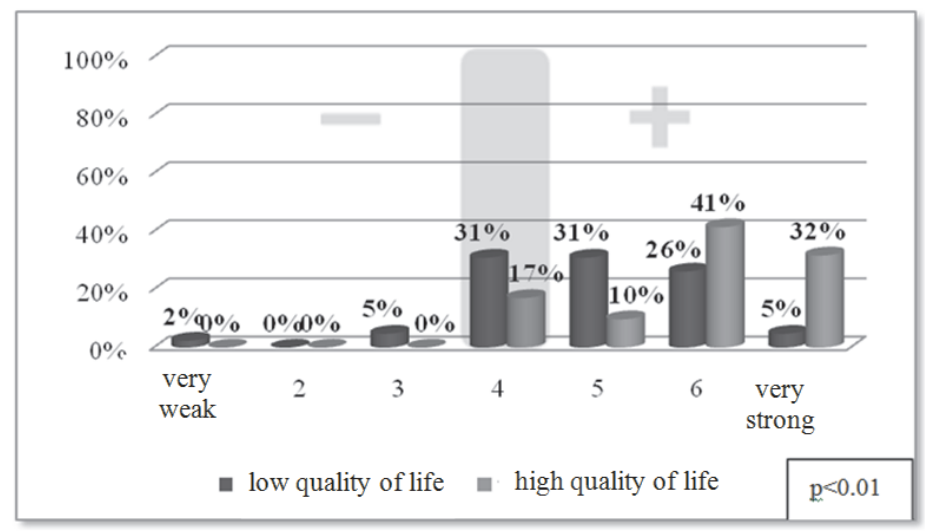

Figure 2. The assessment of family bonds of male students with a low or high level of the quality of life $(n=83)$

In the category describing the level of relations with mates and friends reverse proportions were observed in women, i.e. over a half of the female students who achieved contentment with their lives were "satisfied" with these contacts, whereas a half of the students with a low level of the quality of life were "quite dissatisfied". It was a distressing fact that $7 \%$ of the female respondents from this group indicated the lack of mates and friends. Among male students these assessments were more homogenous, since over a half of them were "satisfied" with their friends and social life, regardless of the level of the quality of life.
Table 2. The level of satisfaction with the social and other dimensions of the life of students with a high or low level of the quality of life $(n=124)$

\begin{tabular}{|c|c|c|c|c|c|c|c|c|c|c|c|c|c|c|c|}
\hline & & & & & cia & Idin & nen & sion & & & & & & & \\
\hline Categories & & & 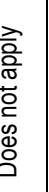 & 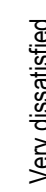 & & t & D. & 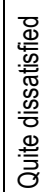 & & 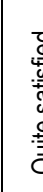 & 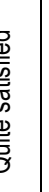 & 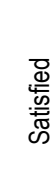 & & 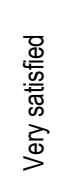 & a \\
\hline & & & & & & & & & & $\%$ & & & & & \\
\hline & & $\mathrm{L}$ & $\mathrm{H}$ & $\mathrm{L}$ & $\underline{\mathrm{H}}$ & $\mathrm{L}$ & $\mathrm{H}$ & $\mathrm{L}$ & $\mathrm{H}$ & $\mathrm{L}$ & $\mathrm{H}$ & \begin{tabular}{l|l}
$\mathrm{L}$ & $\mathrm{H}$ \\
$\mathrm{H}$
\end{tabular} & $\mathrm{H}$ & \begin{tabular}{l|l}
$\mathrm{L}$ & $\mathrm{H}$ \\
\end{tabular} & \\
\hline Relations in a family & W & 0 & 0 & 0 & 0 & 0 & 0 & 13 & 0 & 68 & 7 & 6 & 33 & & \begin{tabular}{l|l|l}
0 & 0.007 \\
\end{tabular} \\
\hline & M & 2 & 2 & 0 & 0 & 2 & 0 & 5 & 2 & 43 & 20 & 413 & 34 & & \begin{tabular}{l|l}
2 & 0.018 \\
\end{tabular} \\
\hline Mates, friends & W & 7 & 0 & 0 & 0 & 5 & 0 & 50 & 7 & 31 & 27 & 6 & 67 & \begin{tabular}{l|l}
0 & 0 \\
\end{tabular} & 0.419 \\
\hline & M & 0 & 0 & 0 & 0 & 0 & 0 & 0 & 0 & 31 & 17 & 525 & 54 & & \begin{tabular}{l|l}
9 & 0.683 \\
\end{tabular} \\
\hline Sex life & W & 47 & 33 & 13 & 0 & 0 & 0 & 0 & 0 & 27 & 13 & 132 & 47 & \begin{tabular}{l|l}
0 & 7 \\
\end{tabular} & 0.452 \\
\hline & M & 7 & 7 & 0 & 0 & 12 & 9 & 22 & 8 & 15 & 22 & 32 & 34 & \begin{tabular}{l|l}
12 & 2 \\
\end{tabular} & \begin{tabular}{l|l|}
0 & 0.727 \\
\end{tabular} \\
\hline & & & & & her & $\operatorname{dim}$ & iens & sions & & & & & & & \\
\hline Life plans & W & 0 & 0 & 0 & 0 & 6 & 0 & 31 & 7 & 50 & 67 & 132 & 20 & \begin{tabular}{l|l}
0 & 6 \\
\end{tabular} & 0.535 \\
\hline & $\mathrm{M}$ & 2 & 0 & 0 & 0 & 9 & 2 & 17 & 10 & 40 & 32 & 25 & 39 & \begin{tabular}{l|l}
7 & 1 \\
\end{tabular} & \begin{tabular}{l|l}
7 & 0.309 \\
\end{tabular} \\
\hline Life achievements & W & 0 & 0 & 13 & 0 & 37 & 20 & 25 & 27 & 25 & 33 & 0 & 20 & \begin{tabular}{l|l}
0 & 0 \\
\end{tabular} & 0.413 \\
\hline & M & 0 & 2 & 7 & 2 & 28 & 10 & 38 & 29 & 24 & 42 & 3 & 15 & \begin{tabular}{l|l}
0 & 0 \\
\end{tabular} & 0.053 \\
\hline Sports achieve- & W & 12 & 20 & 0 & 0 & 19 & 0 & 25 & 7 & 25 & 47 & 192 & 20 & \begin{tabular}{l|l}
0 & 6 \\
\end{tabular} & 0.450 \\
\hline ments & M & 2 & 0 & 5 & 0 & 14 & 12 & 24 & 17 & 36 & 39 & 192 & 22 & \begin{tabular}{l|l|}
0 & 1 \\
\end{tabular} & \begin{tabular}{l|l|l}
0 & 0.359 \\
\end{tabular} \\
\hline Learning results & W & 0 & 0 & 31 & 20 & 25 & 7 & 31 & 53 & 13 & 13 & $\begin{array}{ll}0 & 7 \\
\end{array}$ & 7 & \begin{tabular}{l|l}
0 & 0 \\
\end{tabular} & 0.465 \\
\hline & M & 5 & 2 & 14 & 7 & 31 & 32 & 38 & 42 & 12 & 15 & \begin{tabular}{l|l}
0 & 2 \\
\end{tabular} & 2 & \begin{tabular}{l|l}
0 & 0 \\
\end{tabular} & 0.785 \\
\hline Spending free time & W & 0 & 0 & 0 & 0 & 19 & 0 & 25 & 7 & 44 & 53 & 122 & 27 & \begin{tabular}{|l|l|}
0 & 1 \\
\end{tabular} & \begin{tabular}{l|l|l}
3 & 0.377 \\
\end{tabular} \\
\hline & M & 0 & 0 & 5 & 0 & 7 & 0 & 21 & 5 & 33 & 27 & 24 & 51 & \begin{tabular}{|l|l|}
10 & 1 \\
\end{tabular} & \begin{tabular}{l|l}
7 & 0.042 \\
\end{tabular} \\
\hline Realisation of life & W & 13 & 0 & 13 & 27 & 19 & 20 & 55 & 33 & 0 & 7 & 0 & 13 & \begin{tabular}{|l|l|}
0 & 0 \\
\end{tabular} & 0.341 \\
\hline passions & M & 5 & 2 & 10 & 2 & 17 & 10 & 28 & 20 & 33 & 29 & 7 & 37 & \begin{tabular}{l|l}
0 & 0 \\
\end{tabular} & 0.064 \\
\hline Spending free time & W & 0 & 0 & 0 & 0 & 19 & 0 & 25 & 7 & 44 & 53 & 12 & 27 & \begin{tabular}{l|l}
0 & 1 \\
\end{tabular} & \begin{tabular}{l|l}
3 & 0.377 \\
\end{tabular} \\
\hline & M & 0 & 0 & 5 & 0 & 7 & 0 & 21 & 5 & 33 & 27 & 24 & 51 & \begin{tabular}{|l|l|}
10 & 1 \\
\end{tabular} & \begin{tabular}{l|l}
7 & 0.042 \\
\end{tabular} \\
\hline Prospects for the & W & 0 & 0 & 0 & 0 & 6 & 7 & 31 & 0 & 38 & 40 & 25 & 53 & \begin{tabular}{|l|l|}
0 & 0 \\
\end{tabular} & 0.504 \\
\hline future & M & 0 & 3 & 0 & 0 & 5 & 0 & 24 & 5 & 48 & 39 & & 42 & & \begin{tabular}{l|l|}
1 & 0.121 \\
\end{tabular} \\
\hline
\end{tabular}

* key as in Table 1.

Nearly a half of the female students with a low level and every third female student with a high level of the quality of life had not started sex life. As far as male students in both groups are concerned, it referred to every fourteenth student. However, regardless of gender, the level of the satisfaction with sex life did not differentiate the level of satisfaction with their life to a statistically significant degree.

The complementary questions in the questionnaire show that, regardless of a high or low level of the quality of life, over $70 \%$ of female students and $80 \%$ of male students have somebody who they have good relations with, understand each other very well, who they can confide in and who they expect help from in difficult situations. Male students who described their life as happy, mostly felt loved and trusted $(\mathrm{p}<0.01)$. Their female counterparts with a high level of the quality of life described themselves in a similar way, but in this case it was not a statistically significant value.

Additionally, categories which cannot be classified unanimously in the aforementioned groups but which refer to the spheres of functioning of a human that are significant for the evaluation of the quality of life, i.e. one's own achievements, realisation of one's own passions and plans as well as prospects for the future were included in the analysis (Tab. 2).

It is worth mentioning that a person very satisfied with the realisation of one's own achievements was not found in any of the examined groups, which is a good prognosis for the future, since young people are well motivated for realising long-term aims. Over a half of the students with a high level of the quality of life were satisfied with the realisation of their plans and content with their life achievements $(\mathrm{p}<0.05)$. 
Nearly a half of the female students and nearly every third male student with a low level of the quality of life assessed the level of the realisation of their life aims very badly, out of which group every fifth male and female student pointed to sport while every third female student and every fifth male student to studying.

The last group of questions referred to the summarising assessment of life by respondents both as far as the present moment and the whole life are concerned (Fig. 3).

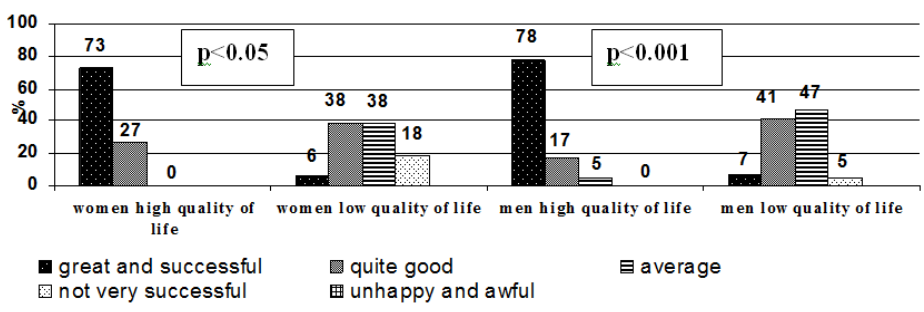

Figure 3. The level of life satisfaction of students with high or low level of the quality of life $(n=124)$

While describing their satisfaction with life in the present days in the categories "not very happy", "quite happy" and "very happy", $35 \%$ of the female students with a high level of the quality of life assessed their lives as very happy, which could not be said by any of their counterparts with a low level of the quality of life. In this case the proportions were reverse, i.e. $38 \%$ of the subjects defined their lives as "not very happy" $(\mathrm{p}<0.05)$. Analogically, among men every fourth student with a high level of the quality of life assessed his life at the moment as "very happy". Similar opinions about their lives were expressed by only one in twenty male students with a low level of the quality of life $(p<0.01)$, whereas every fifth subject from this group was so fed up in the previous months that he thought about suicide quite frequently.

The level of satisfaction of the first-year students of physical education with their whole life is presented in Figure 3.

Over $70 \%$ of both female and male students with a high level of the quality of life assessed their life globally as great and successful $(\mathrm{p}<0.05 ; \mathrm{p}<0.001$, respectively). None of the examined female students in this group assessed her life as average (only $5 \%$ of the examined male students) or as unsuccessful.

\section{Discussion}

"The increase in life stress first leads to the decrease in the satisfaction with these areas in which the situation is bad and then, if the problems are not solved, its effect may spread to a general satisfaction with life and finally lower the subjective eagerness for life" [8]. The meaning of these actions will be verified by the system of values which is shaped since childhood mainly by parents but also by the social environment. Preferring particular values and formulating personal aims and ambitions according to them, may constitute the fundamentals of the feeling of the sense of life [16], "while certain types of life aims (or ambitions) may be connected with psychological or physical well-being of an individual" $[17,18]$ and improve the quality of life [19]. If we note that in the hierarchy of values of $1^{\text {st-year }}$ students love was selected as number one by women and as number two by men [20], we find an explanation to the obtained research results in which female and male students who assess the quality of their lives well are satisfied with their family bonds $(\mathrm{p}<0.05$ and $\mathrm{p}<0.01$ respectively), whereas over $70 \%$ of them assess relations in their families as positive $(\mathrm{p}<0.01)$. However, health is such a value that occurred most frequently as number one among men, which may also be confirmed by the results of the national research carried out among students of seven universities of physical education in Poland [21] and by the description of the Polish population done since the year 2000 in the panel research of Social Diagnosis [15]. Students who are "satisfied" and "very satisfied" with their health (90\%) assess their quality of life well $(\mathrm{p}<0.05)$, which coincides with the results of research carried out in the field of positive psychology [22]. Taking into consideration the fact that "the satisfaction with life correlates with the satisfaction with after-work activity more than with the satisfaction with work" [22], we understand that the students' satisfaction with the ways of spending free time was more significant for the assessment of their quality of life $(p<0.05)$ than the results achieved in studying. It is a thoughtprovoking fact that none of the female students with a low level of the quality of life is satisfied even to a lowest extent with the realisation of her life passions. Presumably, they may not have such passions at all, which might be the source of frustrations. The selection of the course of studies might have been so accidental that it does not guarantee their development or their passions are so specialist that the local urban environment with a biosocial infrastructure does not provide any chance for their realisation. Perhaps the reasons for this state are rooted in the possibilities of these people since, as Kowalik claims [3], "differences in the quality of life may result from an individual's possibilities to utilise information obtained from the surroundings for releasing their own more or less abundant world of experiences".

There are further research results matching this negative trend of assessment which prove that, regardless of gender and the level of the quality of life, approximately $40 \%$ of female and male $1^{\text {st }}$-year students assess the access to the goods of culture and services provided in the town negatively and nearly every third of them are not satisfied to various extents with studying in Biala Podlaska as an academic town. This piece of information is significant for the analysis of the quality of life since "not fulfilling social and socio-psychic needs hinders or even prevents the fulfilment of mental and biological needs" [23]. However, it must be remembered that the aforementioned analyses refer to the students of FPES and generalising the obtained research results for the whole population of physical education students requires further research.

In order to summarise this discussion it may be claimed that "the way in which the world is perceived influences the feeling of happiness more than objective conditions, while the meaning of particular factors in raising mental well-being will depend on values, personal aims, personality and culture of people" [5].

\section{Conclusions}

1. The level of contentment with partial satisfactions was connected with the system of values of an individual.

2. Positive and strong bonds and relations in a family brought about a good assessment of the quality of life by the subjects.

3. The system of cultural institutions in Biala Podlaska as a university town should be developed more dynamically.

\section{Acknowledgements}

The work was accomplished within the framework of research project of the Faculty of Physical Education and Sport in Biala Podlaska, the Josef Pilsudski University of Physical Education in Warsaw - DS.117 - financed by the Ministry of Science and Higher Education. 


\section{Literature}

1. Dziurowicz-Kozłowska, A. (2002). Around the notion of the quality of life. Psychologia Jakości Życia 2, 77-99. [in Polish]

2. Kochman, D. (2007). The quality of life. Theoretical analysis. Zdrowie Publiczne 117(2), 242-248. [in Polish]

3. Kowalik, S. (2000). Mental life quality. In R. Derbis (Ed.), The quality of development versus the quality of life (pp. 11-31). Częstochowa: Wyższa Szkoła Pedagogiczna. [in Polish]

4. Żukowska, Z. (2005). How can sport influence the improvement of the quality of life? Kultura Fizyczna 11-12, 25-26. [in Polish]

5. Diner, E., Lucas R.E. \& Oishi S. (2005). Subjective well-being: The science of happiness and life satisfaction. In J. Czapiński (Ed.), Positive psychology. The science of human happiness, health, strength and virtues (pp. 35-50). Warszawa: Wydawnictwo Naukowe PWN. [in Polish]

6. Trzebińska, E. (2008). Better health owing to bigger happiness. In I. Heszen \& J. Życińska (Eds.), Health psychology - in search of positive inspirations (pp. 23-38). Warszawa: Wydawnictwo SWPS „Academica”. [in Polish]

7. Czapiński, J. (2003). Total happiness. Charaktery 73, 8-15. [in Polish]

8. Czapiński, J. (2004). Psychological theories of happiness. In J. Czapiński (Ed.), Positive psychology (pp. 51-102). Warszawa: PWN. [in Polish]

9. Cieśliński, R. (2009). University education quality system assumptions vs. practice in the context of the Bologna Process. Pol. J. Sport Tourism 16, 135-142.

10. Turosz, M.A. (2006). Social origins and success in studying versus the level of selected dimensions of the quality of life of female and male students of the FPES in Biala Podlaska In J. Saczuk (Ed.), Determinants of the development of rural children and youth (pp. 442-455). Warszawa-Biała Podlaska: AWF, ZWWF. [in Polish]

11. Turosz, M.A. \& Zajkowska-Magier M. (2006). The level of one's own effectiveness and life satisfaction versus aca-

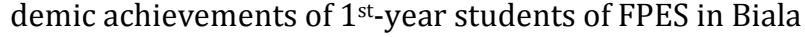
Podlaska coming from rural environments. In J. Saczuk (Ed.), Determinants of the development of rural children and youth (pp. 467-477). Warszawa-Biała Podlaska: AWF, ZWWF. [in Polish]

12. Turosz, M.A. (2009). The level of the quality of life vs. psychological resources of highly trained athletes. In E. Rut- kowska (Ed.), Wellness and success in sport (pp. 207-216). Lublin: NeuroCentrum.

13. Turosz, M.A. \& Bochenek A. (2009). Personality conditionings of life satisfaction of $1^{\text {st }}$-year students of the Faculty of Physical Education in Biała Podlaska. In A. Wolski (Ed.), Wellness and success in sport (pp. 372-380). Lublin: NeuroCentrum.

14. Juczyński, Z. (2001). Measurement tools in health promotion and psychology. Warszawa: Pracownia Testów Psychologicznych PTP. [in Polish]

15. Czapiński, J. \& Panek T. (Eds.) (2009). Social Diagnosis 2009. The conditions and quality of life of the Poles. Report. Social Monitoring Council. Warszawa: WSFiZ, http://www.diagnoza.com/pliki/raporty/Diagnoza_raport_ 2009.pdf (6.05.2011). [in Polish]

16. Oleś, P. (1998). Value Crisis Questionnaire (VCQ). Manual. Warszawa: Pracownia Testów Psychologicznych PTS. [in Polish]

17. Skarżyńska, K. (2003). Life aims, interpersonal trust and life satisfaction. Psychologia Jakości Życia 2(1), 35-49. [in Polish]

18. Rumiński, A. (2004). Axiological dimension of the quality of life. In A. Rumiński (Ed.), The students' quality of life. Kraków: Impuls. [in Polish]

19. Nowacki, T.W. (2007). Attitudes and values - problem outline. In E.I. Laska (Ed.), Teacher education in view of school transformations (pp. 173-192). Rzeszów: Wydawnictwo Uniwersytetu Rzeszowskiego. [in Polish]

20. Chodowicz, E. (2009). The system of values of $1^{\text {st }}$-year students of the FPES in Biala Podlaska with various levels of the quality of life. Non-published BA thesis, WWFiS, Biała Podlaska. [in Polish]

21. Bochenek, A. (2010). A competent physical educator teacher of health. In J. Kirenko (Ed.), Healthy school - healthy student. Between theory and practice. Selected issues (pp. 5969). Lublin: UMCS. [in Polish]

22. Argyle, M. (2005). Causes and correlates of happiness. In J. Czapiński (Ed.), Positive psychology. The science of human happiness, health, strength and virtues (pp. 165-203). Warszawa: Wydawnictwo Naukowe PWN. [in Polish]

23. Zimny, Z. (2000). The quality of human personality development versus the quality of life. In R. Derbis (Ed.), The quality of development vs. the quality of life (pp. 33-39). Częstochowa: WSP. [in Polish]

Submitted: March 22, 2011

Accepted: April 19, 2011 